\title{
Cerca de la revolución: aproximación al estudio de Carlos Astarita sobre los movimientos comunales
}

\section{Close to the revolution: an approach to Carlos Astarita's study of the communal movements}

\author{
Laura da Graca \\ lauradagraca@gmail.com \\ Universidad de La Plata/ Universidad de Buenos Aires, \\ Argentina
}

Recepción: 30 Julio 2020

Aprobación: 01 Septiembre 2020

Publicación: 10 Diciembre 2020

Cita sugerida: da Graca, L. (2020). Cerca de la revolución: aproximación al estudio de Carlos Astarita sobre los movimientos comunales. Sociedades Precapitalistas, 10, e052. https://doi.org/10.24215/22505121e052

\begin{abstract}
Resumen: En el libro Revolución en el burgo Carlos Astarita analiza los movimientos comunales urbanos europeos, el perfil de todos los sectores sociales que participaron de las luchas, sus condicionamientos estructurales y sus motivaciones, la conexión con otras rebeliones, la dimensión religiosa y la aportación del conflicto comunal a la configuración de elementos del Estado moderno y a la teoría política. El objetivo es brindar una aproximación a los contenidos centrales de la obra y a su fisonomía general.
\end{abstract}

Palabras clave: Astarita, Movimientos comunales, Estructuras sociales urbanas, Conflicto social, Disidencia religiosa.

\begin{abstract}
In his book Revolución en el burgo Carlos Astarita analyses the European urban communal movements, the profile of all social strata involved in the revolts, their structural conditions and motives, the connection with other rebellions, the religious dimension, and the contribution of the communal conflict to the formation of elements of the modern State and to the political theory. The aim of this work is to give an approach to the book's main contents and style.
\end{abstract}

Keywords: Astarita, Communal movements, Urban social structures, Social conflict, Religious dissent.

\section{Cerca de la revolución: aproximación al estudio de Carlos Astarita sobre los MOVIMIENTOS COMUNALES1}

Revolución en el burgo es un libro complejo, inusual y repleto de ideas. Se trata de una elaboración muy alejada de los estándares de la producción académica actual: desarrolla problemas teóricos, explicita convicciones de orden filosófico, ejercita constantemente la crítica, extiende la reflexión a problemáticas contemporáneas, aprovecha la tradición del socialismo, establece comparaciones con situaciones de espacios y periodos variados, recurre a fuentes literarias y a informaciones no convencionales, desborda la especialización sin dejar de basarse en documentos y pone en juego un inmenso volumen de conocimientos.

El propósito de estas páginas es ofrecer una aproximación a los contenidos troncales de la obra y a su fisonomía general, lo cual implica, por las características del trabajo, dejar de lado múltiples incursiones y despliegues analíticos que es imposible compendiar. Una parte de la riqueza del libro está en la formulación y en el desarrollo narrativo y conceptual de los problemas, riqueza que se perderá en el trabajo de síntesis, 
que conlleva la simplificación y la omisión de contenidos (y en vista de la estética de la obra, la degradación de los planteos del autor). Aclarado este punto, que es también una convocatoria a leer el libro, iniciamos el recorrido por sus contenidos y propuestas.

Comencemos por el objeto de estudio: los movimientos comunales europeos, sus determinaciones estructurales, el perfil de todos los sectores que participaron de las luchas y la conexión con la dimensión religiosa. En las primeras páginas del libro se plantea que el objetivo central es contribuir al conocimiento de los antecedentes medievales del Estado moderno, o más precisamente, del papel que jugó la conflictividad en esta primitiva configuración de una modalidad de gestión no planeada por la burguesía. Agregaría que la obra también se orienta a comprender el accionar de nuestros antepasados "prepolíticos", a poner de relieve la significación del artesano medieval, a destacar la relevancia de la subjetividad específica de los actores y a reflexionar sobre la lucha revolucionaria en general.

La investigación está centrada en el movimiento de Sahagún, aunque se analizan episodios de otros movimientos comunales y son continuas las referencias a situaciones y luchas de distintos lugares y tiempos. Estas protestas y su contexto proporcionan el material central para la comprensión de los diferentes aspectos que se van analizando. Este es el método, en la práctica, por el que se accede a una unidad problemática y a la explicación del objeto puntual de análisis, que forma el todo en su conexión con otros contenidos del fenómeno. La totalidad que quiere conocer el autor no está dada entonces por la generalización de casos particulares ni por la sumatoria de partes sino por los fundamentos esenciales de las diversas facetas del fenómeno y de sus interrelaciones. Esta totalidad, a su vez, implica procesos de transformación, y por lo tanto es devenir, por lo que dar cuenta de la totalidad es dar cuenta de su movimiento.

La indagación empírica, entonces, es el punto de partida, a diferencia de la metodología que parte de una abstracción externa al fenómeno o de un modelo al cual referirlo; pero esta indagación empírica no es una indagación a ciegas; está guiada por la teoría, que proporciona criterios para abordar la complejidad de lo real y herramientas conceptuales para construir paulatinamente, al compás de lo que revela la observación, el plano de las formulaciones generales. Este proceso de sistematización se inspira en una de las fuentes del materialismo histórico, la doctrina del desarrollo de Hegel, y se nutre de la elaboración teórica marxista, del horizonte general de reflexión de esta corriente y de contribuciones provenientes de diversas corrientes y disciplinas.

El autor resume la epistemología que va a seguir como "análisis de totalidad, totalidad como esencia y aprehensión conceptual del movimiento contradictorio del ser”, lo cual expresa un alineamiento (Aristóteles, Hegel, Marx) que se opone a otro, el de las teorías del conocimiento que parten del ser de la idea, de categorías trascendentes o de tipos ideales (Platón, Kant, Weber). Esta oposición se hace presente en diversos momentos del libro, el cual de hecho comienza contrastando las interpretaciones de los movimientos comunales regidas por una idea o un modelo con las que captan el devenir del proceso histórico desde el estudio de la práctica social concreta; frente a estas interpretaciones, podría decirse que el autor va a desarrollar el potencial de lo que queda en pie, y en términos de la concepción marxista de la crítica, explicar lo que quedó sin explicar.

La primera parte del libro recorre la historiografía sobre el tema y puntualiza criterios teóricos y metodológicos. La visión clásica es el punto de partida, pero no en la formulación de Pirenne, centrada en la acción del comercio, sino en la de su antecesor del siglo XIX Augustin Thierry (1795-1856), que a diferencia de Pirenne jerarquizó la participación de las masas, la vocación de poder de los protagonistas y el hecho de que hayan conseguido la libertad y las comunas por medio de la lucha, lo que emparenta las revueltas del XII con las revoluciones burguesas del XVIII y XIX. La concepción de la ciudad como elemento dinámico opuesto a la servidumbre rural será luego el núcleo de la interpretación liberal positivista, llamada a destacar el efecto disolvente de la circulación de mercancías y el papel de su agente principal, el mercader de larga distancia, que va logrando avances en la conformación de las bases jurídicas y políticas que requiere el despliegue de su actividad (la cual expresa un impulso natural que atraviesa todos los tiempos, un componente del enfoque de mercado consolidado en sus versiones actuales). 
El enfoque de Pirenne, replicado por otros autores, como sabemos fue discutido y objetado en los años 40 y 50 por los historiadores marxistas británicos (y debemos agregar, por los demografistas) hasta quedar reducido al rango de pieza de museo, al menos en lo relativo al papel del gran mercader. La idea de integración entre capital mercantil y feudalismo pasó a dominar el panorama, y en el recambio las revueltas urbanas descendieron a la categoría de episodios poco relevantes para la transformación social, de la mano del estatuto que se le daba al comercio; asociadas al enfoque liberal, las revueltas comunales perdieron interés como objeto de estudio. El estado de la cuestión se ordena en torno a este cambio de paradigma, y por sus muchas páginas desfilan los pequeños aportes de los que minimizaron las luchas de los habitantes del burgo, adaptaron su caso de estudio al modelo dominante (en algunos casos sin advertir que replicaban la noción de externalidad del comercio) o se sometieron a la influencia de la escuela de los Annales, que impuso la prioridad de la historia agraria y relegó la transformación política como problema; entre los autores españoles las revueltas comunales quedaron asociadas al institucionalismo, y el modesto tratamiento del tema se relaciona aquí con el imperativo de tomar distancia de Sánchez Albornoz. Las revueltas también fueron tratadas como episodios de la disputa por el poder o como expresión de inestabilidad política, esta vez en sintonía con el enfoque mutacionista. No faltan aportes puntuales que el autor considera útiles, pero hay que buscarlos fuera de la historiografía más conocida.

Las revueltas comunales, en suma, en términos generales fueron desestimadas por los historiadores y/ o abordadas como ilustración de un modelo. En este panorama Astarita destaca una nota discordante: el estudio de José Luis Romero, que si bien se apoyó en el esquema de Pirenne enfatizó la conflictividad, como Thierry, y consideró la práctica social de los diversos actores, que no se resumen en el hombre de mercado. En un escenario de múltiples tensiones, especialmente allí donde enfrentaban a eclesiásticos, estos actores fueron configurando sus objetivos en el transcurso de sus luchas hasta confluir en un perfil cultural y político novedoso, el cual conecta las revueltas del XII con un problema que las trasciende, el origen de las mediaciones que expresan el rasgo central del Estado moderno. Astarita presenta la contribución de Romero como un estudio del devenir de la totalidad, estudio con el cual dialogará a lo largo de la obra y al que homenajea desde el título del libro.

No es casual que Thierry y Romero sean los únicos autores mencionados en los subtítulos; los demás quedan subsumidos en la neblina de rótulos tales como "Ostracismo del tema", "Otras deserciones de la visión clásica”, etc., lo que los devuelve al lugar que dieron a las insurrecciones urbanas o a la opacidad de sus contribuciones. El balance historiográfico arroja otras brumas: según observa el autor no queda claro quiénes eran los burgueses (¿mercaderes, artesanos, capitalistas?), ni se prestó atención al pueblo que los acompañaba (menestrales, aprendices, pobres, marginados), ni a los líderes, ni a las mujeres, ni a los clérigos que se opusieron a sus prelados. En relación a este punto el autor va a poner de relieve la vinculación entre disidencia religiosa y movimientos comunales, asociados también a herejías.

Puesto que la dimensión religiosa y el carácter plural del conglomerado social que participó de las luchas son problemas centrales a tratar, el balance historiográfico se extiende a la consideración de estudios sobre anticlericalismo, y se trata la cuestión de cómo aprehender conceptualmente la diversidad social.

Respecto al anticlericalismo (en rigor, "tendencias antisacerdotales"), el autor rebate cada uno de los argumentos que se dieron sobre el origen y la difusión de la nueva religiosidad (influencia del Evangelio, del misticismo, de la filosofía, de los predicadores, de las escuelas urbanas, de la comodidad del tejedor para leer, etc.), y en cambio se detiene en el concepto de "afinidades electivas" de Weber, que señala la adecuación o atracción mutua entre el espíritu capitalista y la ética religiosa que promueve la superación del estado de naturaleza; plantea que si bien el concepto no postula una relación de causalidad sino la idea de confluencia entre tendencias económicas y religiosas, confiere primacía a la esfera de la subjetividad, que dicta una elección racional al artesano o al mercader en relación a una religiosidad que conviene a su perfil económico. En oposición a esta forma de aproximación al problema Astarita va a seguir el criterio materialista según el cual las 
cualidades del trabajo condicionan la elección religiosa, que no es una elección deliberada sino un producto social, y que debe entenderse desde el concepto marxista de alienación.

En cuanto a la diversidad de situaciones que reflejan las fuentes sobre los protagonistas de las revueltas, el autor cuestiona a quienes en el afán de dar cuenta de la gama de actividades y nexos del sujeto social diluyen la prioridad del posicionamiento de clase, y a la vez advierte sobre el carácter insuficiente de un análisis asentado solamente en las estructuras. La salida a este problema es el concepto de clase estamental, que da cuenta de la esencia, dada por el lugar en la producción, y de los atributos jurídicos, ideológicos y culturales que componen el estatus. Astarita argumenta que una vez constituida la relación de explotación (que se construye a partir del estatus, lo que da cuenta de la relación dialéctica entre ambas categorías), la posición de clase determina los límites del rango, pero esta base objetiva no puede explicar la especificidad de la práctica social ni el pasaje de la aceptación de las condiciones dadas a su no aceptación, que en cambio puede pensarse, al menos para las elites urbanas, en términos de no correspondencia entre los atributos estamentales anexos a la posición de los sujetos en el sistema de clases y las condiciones jurídicas y políticas a las que aspiran esos sujetos, que pasan a la acción para alcanzarlas.

Entre los sectores populares este salto es más difícil de explicar, y aquí cuentan factores como la sensibilidad o el estado de ánimo; para conocer cómo procesaban los actores las condiciones objetivas de su existencia el autor propone incursionar en fuentes literarias, que abren el acceso al micromedio y a la psicología de los personajes, y tomar en cuenta aportes puntuales de la sociología. En relación a la temática del libro, centrado en la lucha política, el autor explicita los apoyos menos formalizados de su elaboración, como los que provienen de la experiencia de la lucha revolucionaria, y en especial la influencia de la teoría marxista de la política, cuyo referente principal es la obra de Antonio Gramsci.

En relación a las luchas de los sectores populares se considera críticamente la contribución de los estudios sobre subalternidad, focalizados en problemáticas coloniales y orientados a rescatar la voz de los oprimidos en relación a elementos culturales o a las condiciones de sometimiento. En la visión de Astarita la inclinación de esta escuela a descansar en el registro empírico tiene un paralelo con la concepción de E. P. Thompson sobre la moderna conciencia de clase, surgida según Thompson por experimentación de las condiciones de sobreexplotación y asimilada a la conciencia del antagonismo con otra clase antes que al conocimiento del fundamento de la explotación, conocimiento que de acuerdo al marxismo ortodoxo debe ser atribuido dado que no es evidente. La valoración de Thompson de la conciencia real y su consiguiente negación de la necesidad de la teoría señala una discrepancia clave con la visión de Astarita, y en particular en relación al libro que estamos analizando, el cual le otorga un lugar central a los intelectuales y a diversos elementos que mediaron entre la experiencia de la lucha y la subjetividad de los actores.

Si bien la inclinación a "ceder la palabra al sujeto" señala confluencias entre los historiadores marxistas británicos y los que estudian la subalternidad, éstos rechazaron el concepto de "gente prepolítica" de Hobsbawm, en vista de que niega conciencia de clase a sujetos conscientes de su identidad étnica o de la sujeción colonial, lo cual, advierte Astarita, descubre el desconocimiento por parte de esta escuela del concepto de conciencia de clase, relativo a la cognición de la estructura, entre otras determinaciones. Frente a ésta y otras objeciones de los historiadores de la subalternidad al carácter arcaico del subalterno precapitalista, Astarita considera válida la categoría de sujeto prepolítico (y de hecho dedica el libro al proceso de formación del sujeto político), aunque a diferencia de Hobsbawm defenderá que el subalterno precapitalista puede tener conductas políticas y un lenguaje preciso, que en todo caso hay que descifrar con la intervención de herramientas científicas.

Así como la conciencia de clase es el momento subjetivo de la estructura, la reflexión que sigue (el capítulo denominado "Crítica y teoría") es "el momento subjetivo de la obra", en el que el autor expone sus convicciones respecto a la centralidad del concepto de determinación y al criterio metodológico con el que elaboró el libro, fundado en la vertiente hegeliana del marxismo. Frente a los historiadores que descalifican la noción de determinación en la creencia de que se limita a la idea de que la base determina mecánicamente 
a la superestructura, recomienda tener en cuenta que la imagen refiere más ampliamente a los límites en que se desenvuelve la acción, los cuales no dejan de ser producto de la actividad humana. La noción de determinación implica saber cuál es la esencia de lo que tiene existencia real ("qué es lo que es"), con lo cual volvemos al contraste entre filosofías del conocimiento fundadas en entidades trascendentes o en el mundo de los objetos. El autor opone aquí la noción de determinación de Kant y la de Engels de determinación en última instancia, que aspira a acceder a la esencia que hace comprensible una totalidad mediante sucesivas abstracciones surgidas de la observación sistemática: se trata de captar la dialéctica histórica, por lo que el libro en teoría es el fruto de la dialéctica del pensamiento. El autor no pierde la esperanza de que "algún día la razón deje de adaptarse a la irracionalidad de lo real y se organice lo real de acuerdo al dictamen de la razón”.

En cuanto a la dicotomía determinación/acción del sujeto, advierte que refleja una contradicción de la realidad histórica, dado que hay momentos en que el sujeto modifica las condiciones de su existencia, por largo tiempo inalteradas; el énfasis en uno u otro término de la ecuación no viene entonces dictado por una elección del investigador sino por el objeto de estudio, que es el que va a imponer los diversos tipos de literatura de apoyo y los recorridos comparativos a los que apelará el autor a lo largo de la obra, según deba centrarse en la estructura o en la acción de los sujetos.

La segunda parte del libro está centrada en la estructura. Se analizan las bases objetivas y la manera en que impactan sobre la subjetividad de los actores. El estudio estructural del área incluye el análisis del origen del burgo y el mercado de Sahagún y del artesano en general, para lo cual nos remontamos a los tiempos de las sociedades de base campesina y su transformación. Veamos lo esencial.

$\mathrm{Al}$ igual que otros centros religiosos europeos, el monasterio de Sahagún tiene su origen en un santuario. Situado en el medio rural, el lugar de culto convoca a los habitantes del entorno y extiende su influencia a medida que crece la fama del santo y con ella el tráfico de favores y ofrendas. Éste se inscribe en el intercambio de regalos, propio de una sociedad sin extracción regular de excedente, y armoniza con la religiosidad centrada en el rito propiciatorio, propia del labrador sujeto al dominio de la naturaleza. El flujo de donativos al templo estimula la especialización en la tarea de mediar entre los pobladores y la divinidad, y en la medida en que el sacerdote vive de estos donativos la diferencia de función se transforma en diferencia de clase, y la reciprocidad en explotación del trabajo. Esta evolución explica el interés de los religiosos por preservar o conseguir reliquias, y se complementa con dotaciones regias, patronato político y concesión de inmunidades. En este contexto de expansión, que es también de crecimiento urbano, hay que situar la configuración del burgo, que surge por evolución de la congregación de monjes, intervención del poder superior y crecimiento del conjunto de edificaciones que rodean al santuario, y que se asocia a la importancia creciente del centro señorial y al papel de intermediación entre este centro y los pobladores del dominio. El burgo, que luego alcanzará el estatuto de villa, no es entonces producto de agentes externos al medio rural y señorial, como proponía Pirenne, sino de un conjunto de factores entre los que hay que contar la religiosidad campesina.

El contexto de la sociedad de base campesina que explica la dinámica originaria del santuario también es el punto de partida del artesano medieval. El autor desarrolla una explicación sobre el origen de los oficios: éstos no surgen por la evolución de la división del trabajo sino por las condiciones que requiere el despliegue de las cualidades del trabajo artesanal (pericia, creatividad, baja intensidad de trabajo, concentración, aprendizaje prolongado, transmisión generacional). Estas condiciones habrían sido dadas por la unidad doméstica campesina en el marco de las estructuras sociales que se desarrollaron entre la disolución del estado antiguo y la difusión del señorío banal. El autor sitúa el origen de la especialización artesanal en las necesidades de consumo de la aristocracia temprano medieval, que en el contexto regresivo recurre a la instrucción de esclavos domésticos. Se configura así un segmento servil productor de artesanías (herreros, carpinteros, etc.) que por la naturaleza creativa de su actividad y el ritmo no intenso de trabajo se distingue de los sirvientes con funciones domésticas y de los esclavos rurales de propiedades fundiarias; el reconocimiento hacia este sector que se separa de otros cuestiona el tópico de una descalificación general del trabajo por parte de la aristocracia. 
La debilidad del control social y del Estado, característica del periodo, favorece la huída de esclavos, muchos de los cuales son artesanos que se instalarán en aldeas y burgos, incorporándose en unidades productivas familiares. Esta evolución responde a las características de la unidad campesina, que por su aspiración a la autosuficiencia admite en su seno actividades secundarias, y a la política señorial, que propició en muchos casos la instalación de esclavos, con lo cual favoreció la integración y promoción social de los fugitivos, contrariamente a otras sociedades donde el esclavo que huye se convierte en marginal. Este desplazamiento del esclavo especializado desde la casa señorial a la tenencia favorece la conservación del oficio y el aumento de la productividad del trabajo, resultado de la exigencia de renta por parte del señor, y en particular, de renta en productos terminados. La unidad de producción donde se radica el servus especializado contribuye al desarrollo de los oficios: en tanto ámbito privado, estimula la concentración y la preservación del oficio en la familia; la explotación familiar del trabajo proporciona un modelo de coacción que favorece el aprendizaje y prefigura la autoridad del maestro artesano, y a la vez proporciona un modelo de adaptación a las necesidades cambiantes del ciclo familiar (incorporación de sirvientes, etc.) que conduce al empleo de asalariados, lo cual implica un potencial para la producción de valores de cambio en la tenencia que produce manufacturas. El siervo artesano se encuadra en la unidad doméstica aldeana, pero a la vez se separa de ella por el carácter teleológico de su actividad, cuyas derivaciones se desarrollarán más adelante. La valoración social de los oficios es un aspecto clave en la constitución de la subjetividad específica del artesano, ya que afirma su autoestima y promueve la fijación y transmisión del saber, contrariamente al esclavo recluido en recintos especiales, donde la difusión del oficio está limitada por la falta de socialización. La valoración social de la manufactura favorece también la migración hacia los asentamientos de artesanos y la colocación de miembros de familias de localidades del entorno como aprendices en talleres artesanales.

Los primeros artesanos, entonces, no surgen del desposeído errante que se instala en las cercanías de una residencia señorial, como proponía Pirenne; su desarrollo, en cambio, tiene como condición la explotación parcelaria individual, lo que por otro lado restringe esta evolución a los sistemas con base en la apropiación individualizada de las condiciones de producción.

En el espacio señorializado y sacralizado por el culto al santo se desarrolla el intercambio mercantil y la circulación de moneda, de lo cual se ofrece evidencia empírica de mediados del XI. Estas novedades operan sobre intercambios informales preexistentes que conectaban zonas de distinto perfil productivo (de valle y de montaña), a lo cual se suman otros circuitos como la ruta de peregrinación a Santiago o la salida al Cantábrico, al igual que sucede en otros lugares en los que un centro urbano es el punto de confluencia de zonas productivas diferenciadas y rutas comerciales. Estos intercambios informales se irán reglamentando hasta constituir mercados regulares y ferias, cuya fisonomía responde a requerimientos señoriales de extracción de renta y de articulación de las economías campesinas del entorno.

El desarrollo de la circulación monetaria y mercantil contribuye a distanciar a los pobladores de la divinidad local, cuya forma concreta, que impregnaba el espacio, ahora compite con fuerzas impersonales; si el mercado tiene un efecto disolvente éste se encuentra en la esfera de la subjetividad. Asimismo, es el pequeño comercio el que interesa y no el que tiene como agente al mercader de larga distancia, que por otro lado no tendrá protagonismo en la revuelta de Sahagún. Siguiendo a Hilton, el autor valora el grado de mercantilización de las economías locales antes que el gran comercio, al igual que los exponentes del nuevo enfoque de comercialización (Britnell, Epstein, North y Thomas), enfoque del cual deplora los fundamentos, centrados en la evaluación que realizan los actores acerca de la conveniencia de volcarse al intercambio, una concepción que además de asumir la universalidad del hombre de mercado presupone un devenir más o menos libre de contradicciones. Contra el individualismo metodológico, observa que en el surgimiento del mercado concurren la lógica campesina, la lógica señorial, la religiosidad, la intervención política, la difusión de la moneda, resabios de economía natural, etc., y que los instrumentos del comercio se adaptan a la práctica existente. 
Aunque en la feria se comercializa pañería suntuaria, este tráfico no involucra a los artesanos de Sahagún, caracterizados por oficios de baja especialización. La destrucción de bienes de prestigio durante la revuelta es uno de los argumentos para descartar la participación de agentes del gran comercio, que por otro lado no tendrían interés en enfrentar a sus clientes ni a poderes que en términos generales favorecieron este tipo de intercambio. De las crónicas se deduce que los insurgentes no tenían privilegios; en cambio se los presenta como vasallos sometidos por fuero a diversas imposiciones del abad. Éstas quedan comprendidas en el concepto de dominio político sobre la persona, concepto que señala la gama de obligaciones que pesan sobre aquellos que, a diferencia del esclavo, no son tratados como cosa. Esto nos aleja de la noción de la ciudad como reducto de hombres libres.

Astarita considera el significado de la palabra "burgo", con connotaciones muy variadas, y que en el caso de Sahagún refiere a un núcleo apenas diferenciado del entorno rural (sería un "burgo rural con aldeas"). Esto matiza el dualismo ciudad-campo en los términos de la historiografía liberal, pero no anula el contraste entre la ciudad como centro de gobierno y lugar del mercado y la manufactura, por un lado, y el alfoz rural por otro (ni otras diferencias que el autor desarrollará más tarde, relativas al sujeto social). Asimismo, la propiedad de derechos políticos se traduce en monopolios que afectan la actividad comercial de pequeños productores, como la prioridad del monasterio para vender vino, y que generan tensiones, como la prioridad para comprar la leña que abastece el horno señorial, la banalidad que dará comienzo al conflicto.

A diferencia de conglomerados urbanos como los de Flandes o Italia, donde la producción de manufacturas se desarrolló con cierta autonomía, la situación de Sahagún se asemeja a la de las ciudades inglesas que describió Hilton, intervenidas por el poder señorial, aunque la debilidad de la manufactura no impide que se desarrolle un régimen de producción mercantil de base agraria y urbana. El autor compara el primer fuero de Sahagún con el de 1152, en el que se conmutan los monopolios mencionados por pagos en dinero y se modifica la forma de valuar el monto de un censo favoreciendo ahora a los más ricos. Estos nuevos fueros, considerados "buenos", no implican merma de ingresos para el señor, por lo que no pueden asociarse a la conquista de libertades, aunque los cambios impliquen mejores condiciones de existencia para los pobladores, como ocurre de manera general cuando se conmutan prestaciones de trabajo.

Para definir la condición de los habitantes del burgo Astarita apela al concepto moderno de servidumbre, relativo no a las restricciones específicas que puntualizó Marc Bloch, de las cuales los burgueses podían verse liberados, sino a distintos grados de sujeción de los poseedores de medios de producción, sujeción que se identifica con la relación de renta. Pero si la servidumbre los iguala, los niveles de fortuna indican una situación de diferenciación social, e incluso enfrentamientos entre la elite del burgo y sectores campesinos a los que tomaron tierras durante la revuelta. La práctica de ocupar espacios agrarios indica el sustrato campesino de la elite (y también sugiere el protagonismo del sector en la expansión del frente agrícola), así como las dimensiones de algunas explotaciones de artesanos indican producción para el mercado.

El autor observa que esta evolución de la estructura social se refleja en el cambio de sentido del término "burgués", que en el XI designa, en general, al habitante del burgo, mientras que en el XII tiene connotaciones relativas a una posición social distintiva, hasta generalizarse la idea de "persona urbana acomodada"; este cambio semántico aparece, con matices, en casi todas partes. En algunas ciudades tendrá más peso dentro del grupo el mercader; en Sahagún tendríamos "una multiplicidad de artesanos tributarios poseedores de tierras en posiciones expectantes"; en todos los casos analizados los residentes urbanos tienen bienes o intereses en el campo circundante, lo que nos aleja del cuadro clásico del burgués opuesto al ámbito rural.

$\mathrm{Al}$ respecto, se consideran diversas cuestiones: la prosperidad de la elite tropieza con el marco señorial, que limita, por ejemplo, la posibilidad de adquirir tierras o de aprovechar pastos; estos sectores combinan el objetivo de autoconsumo y el de ganancia, y de hecho el capitalista del futuro proviene "de bastardas formas mixtas" (aquí el autor ejemplifica con un personaje de Eugenia Grandet-que reduce su consumo para vender más- la forma en que se abre paso el perfil psicológico del que persigue el beneficio); por útimo, no obstante el peso de la base agraria, es la manufactura lo que define al burgués. 
Aun cuando los negocios de las oligarquías urbanas hayan sido múltiples, el afán de ascenso social es el denominador común. El autor observa que ciertos artesanos (tejedores, zapateros, sastres, etc.) aparecen actuando como testigos o al frente de asuntos locales en el medio rural, lo cual los define como burgueses o como notables de las comunidades; estas actividades complementan el estatus que proporciona ejercer un oficio. El interés en la función de gestión como fuente de estatus, de lo cual deriva la aspiración a una organización propia, será entonces la fuente principal de conflicto allí donde el señor no reconozca esta demanda. Tenemos aquí una situación de no correspondencia entre la posición económica, de relativa prosperidad, y las aspiraciones políticas relativas al estamento, lo cual explica la naturaleza del conflicto.

Respecto al reconocimiento social del oficio el autor reflexiona sobre el carácter no alienado del trabajo del artesano. El hecho de que el artesano se realice individualmente en el trabajo y esta realización le asegure prestigio en la comunidad es una premisa de la conciencia social, aunque el contexto de desarrollo de los oficios (regulaciones, competencia) estimula el individualismo, con lo cual, al igual que sucede en el ámbito rural, el potencial para el desarrollo de una conciencia crítica no se traduce en conciencia de clase. El reconocimiento social hacia el artesano tampoco es un fenómeno generalizado; en algunas ciudades aparece cierto prejuicio hacia el perfil transgresor del artesano, asociado también a la deshonestidad.

Este componente es marcado en la percepción de la actividad mercantil por parte del pequeño productor, lo que dificulta la integración social del comerciante. La contradicción entre la lógica de consumo y la del valor de cambio está en la base de este antagonismo y del que se plantea con el señor, a quien el mercader explota a través del sobreprecio de los bienes de lujo. El autor considera el comportamiento oscilante del mercader, cuya cercanía con el señor puede llevarlo a abstenerse de apoyar una revuelta o a participar activamente, lo cual sucede en algunas ciudades; un atropello a su persona, el deseo de promoción política, la prédica eclesiástica contra el comercio y la usura o el hábito de transgresión sistemática, implícito en la actividad mercantil del periodo, son algunos de los factores que pueden favorecer esta participación.

En las revueltas urbanas participaron también sectores provenientes de los escalones inferiores de la aristocracia y servidores de la administración señorial, como los ministeriales. El autor se refiere a este tipo social, que puede alcanzar cierto enriquecimiento a costa del señor y que se caracteriza por el abuso de autoridad hacia el campesino. El análisis se orienta a delinear su perfil psicológico, para lo cual se dan cita personajes de la literatura del siglo XIX y del siglo XX o figuras históricas que describen las crónicas; este perfil combina el rencor de clase y el deseo de promoción, deseo que a diferencia del caso de otros subordinados (aprendices, juvenes de la aristocracia) no tiene chances de realizarse en el marco de la relación de dependencia. El caso de los Erembald de Flandes, que llegan a encumbrarse sin que nunca se olvide su origen modesto y que por este motivo acaban desatando una revuelta ilustra el efecto del desprecio señorial, y también la persistencia de la noción de linaje, que el autor opone al naciente criterio burgués que valora al que se hace solo.

Se refiere luego al sector de "mancebos". El peso de la renta y de la multa, el endeudamiento, la muerte del cónyuge y el impacto de las obligaciones tributarias sobre situaciones de vulnerabilidad asociadas a infortunios naturales son algunos de los factores que explican el empobrecimiento. Si bien esta condición no necesariamente conduce a la marginalidad, los hijos de los sectores empobrecidos proporcionan aprendices, menestrales, artesanos pobres, etc.

La situación del asalariado del taller artesanal se presenta, en principio, como no conflictiva, dado el ámbito compartido de trabajo y el tono paternalista de la relación entre maestros y oficiales, sin que esto implique asumir que estemos en presencia de la pasividad absoluta del subordinado a un vínculo patriarcal; el interés del aprendiz en llegar a establecerse y la oposición objetiva que implica el salario o el estilo de vida dan lugar a comportamientos oscilantes. Distinto es el caso de la población flotante de los menesterosos y dependientes ocasionales, sin perspectivas de instalación, que el autor compara a los niños que se embarcaron en expediciones de cruzados; la revuelta comunal se presenta aquí como una forma de encauzar la irritación o la rebeldía. 
La participación de mujeres se explica tanto por la búsqueda de independencia como por el afán de que ascienda el marido. El autor analiza formas específicas de violencia contra la mujer (se refiere a la conducta del molinero y al derecho de pernada), que se inscriben en última instancia en la violencia de clase. Asimismo, la posición de la mujer en la unidad doméstica, de la que es miembro primario y garante de la reproducción biológica, explica el autoritarismo patriarcal, fundado en la prioridad de la potencia física en la actividad productiva y en la necesidad de resguardar a quien asegura la continuidad de la especie; contribuye a la subordinación de la mujer la doctrina eclasiástica que consagra su inferioridad. La posición de la mujer en la unidad doméstica explica la ausencia de reclamos sectoriales, porque esa unidad doméstica es a la vez el fundamento de su opresión y de su vida y la base de la economía precapitalista; la liberación de la mujer supone entonces su alejamiento de la casa total. El feminismo, en suma, se abrirá paso cuando la unidad productiva sea la fábrica y no la unidad doméstica.

Las revueltas urbanas se sitúan en el contexto de expansión, a la cual contribuyó el trabajo del artesano, por ejemplo creando herramientas que elevaban la productividad del trabajo agrario. En este marco de crecimiento se hace más evidente el obstáculo que representan las imposiciones señoriales, especialmente para el tributario rico; el control del mercado, entonces, no es el objetivo de las luchas, que al menos en el caso de Sahagún se inician ante banalidades que afectan economías agrarias.

La prosperidad de un sector de los pobladores presupone un proceso de diferenciación social campesina en épocas tempranas. El autor propone como elementos centrales de esta diferenciación la mayor posibilidad de instalación, que favorece una edad temprana de casamiento y con ello familias más numerosas que aportarán más trabajo, y la capacidad de incorporar mano de obra extrafamiliar (asalariados, yugueros) lo que implica que la renta en parte se satisface con la ganancia surgida de la explotación de trabajo ajeno, y que esta ganancia eventualmente puede reinvertirse. Estos sectores acomodados, que no se definen por su localización rural o urbana sino por el perfil de sus economías, son caracterizados como productores simples de mercancías, lo que indica un sistema de base doméstica (que no excluye el trabajo asalariado) en el que la producción de un excedente comercializable ya se ha regularizado sin ser el objetivo principal. La capacidad del tributario enriquecido de generar su propio régimen económico lleva al autor a la siguiente reflexión: la clase feudal, en tal caso, no explota al campesino o al artesano directamente sino con la mediación de un régimen de producción mercantil; no se trata entonces de una relación entre clases sino de una relación entre sistemas que en todo caso se enfrentan a través de las clases, siendo el concejo la expresión institucional de esta mediación.

La presencia de tributarios enriquecidos implica matices en la relación social de renta pero no anula su centralidad, que determina en última instancia la intensidad del trabajo y el desarrollo de las fuerzas productivas. Al respecto, el autor concuerda con Guy Bois en lo relativo al potencial productivo de la tenencia no sujeta a prestaciones de trabajo, pero se distancia a la hora de evaluar los efectos de la erosión de la renta, ya que la parte del producto ganada al señor puede redundar en mejoras técnicas y no solamente en beneficio del consumo familiar, que no es un problema para el tributario rico. La contribución cualitativa al desarrollo de fuerzas productivas por parte del artesano es otro aspecto que objeta el enfoque maltusiano en general, ya que expresa una dimensión inmaterial cuya relevancia se aprecia en el contraste con la dinámica capitalista, que anula las facultades racionales del trabajador, lo cual llama a revisar el criterio de los medievalistas que limitan el análisis al estado de la técnica o asumen que el crecimiento sólo puede ser extensivo.

Puesto que los burgueses lucharon por el autogobierno, el autor analiza las tendencias en cuanto a la voluntad de delegar poder por parte de los señores y los antecedentes o el origen de comunas y comunidades, sobre lo cual ofrece una explicación general (y en la primera parte del libro, un balance historiográfico). Veamos este problema. Así como las comunidades libres se rigen por la asamblea de vecinos, las dependientes se rigen por la asamblea presidida por la autoridad política del distrito. Éste es el caso del área leonesa, que a diferencia de la zona de frontera comparte los rasgos de las regiones centrales del feudalismo. En este contexto, que niega a los pobladores el autogobierno pero a la vez estimula cierto desarrollo organizativo, cobran importancia figuras destacadas de la comunidad, referidas en los diplomas como boni homines, cuya 
función es interceder ante el señor en representación o defensa de vecinos en problemas (por ejemplo para que se mitigue la pena por la comisión de un delito). La función de mediación, a la que se suman tareas de gestión de recursos agrarios, genera instancias deliberativas complementarias a la asamblea de distrito, las cuales irán ganando terreno a medida que crecen los requerimientos económicos propios de una etapa de expansión y con ellos el nivel de conflicto. Esta evolución, que se percibe en el incremento de funciones a cumplir por la comunidad y que expresa el paso del palatium al concilium, culmina cuando el señor confiere entidad institucional a las organizaciones informales de base, lo cual le permite desentenderse de los asuntos locales y consagrarse a tareas propias del estamento. La reorganización de la clase de poder, que acompaña la fase expansiva, es el contexto en el que hay que situar este cambio. La tendencia a regularizar la fiscalidad es otro aspecto de la fase de crecimiento, que se refleja en la simplificación de la exigencia señorial en una renta fija, lo cual se observa en las cartas de franquicia. Éstas no implican entonces liberación de cargas (cuya tasa incluso puede aumentar dado el aumento de productividad de las economías campesinas), pero sí mejores condiciones para los productores.

La centralidad de las instituciones de gobierno en sociedades precapitalistas se explica por la necesidad de una instancia superior de articulación de las unidades domésticas y por la ausencia de mecanismos económicos de reproducción social. La comunidad superior en el modo tributario, la polis en la sociedad clásica, la comunidad en el modo germánico (o en el modo de producción campesino, faltaría añadir) cumplirían esta función, que en la sociedad moderna cumple el mercado. En cuanto al modo de producción feudal, en su etapa formativa este papel lo cumplieron las autoridades políticas, que en el proceso transmutaron la diferencia de estatus en diferencia de clase, y una vez consolidada la relación de explotación, mayormente cumplieron el papel de articulación las comunas urbanas y las comunidades rurales, que mediaron entre el señor y los pobladores sujetos a renta.

Este tránsito del gobierno directo a la mediación de sectores no feudales tuvo distintos grados de aceptación por parte de los miembros de la clase dominante, por lo que se analizan las determinaciones de la actitud de los señores y las tendencias generales, que indican que los laicos se inclinaron a aceptar las comunas, con algunos matices circunstanciales, mientras los eclesiásticos opusieron resistencia. Entre los laicos hay diferencias entre la monarquía, más favorable a delegar poder, y el resto de la aristocracia, y el autor tiene en cuenta también la estructura social de las comunidades, cuyo protagonismo político es mayor cuando se encuentran más estratificadas, lo cual se relaciona con distintas tipologías de señorío. Entre las razones por las que los señores laicos aceptaron delegar poder destaca la necesidad de organizar la defensa militar, de gestionar territorios extensos y de ahorrar gastos de traslado; el perfil estamental, que demanda desplazamientos continuos, y la mayor eficacia de los agentes locales para la recaudación de la renta son otros de los motivos por los que este sector de la aristocracia accedió a delegar funciones de gobierno en organismos surgidos de las comunidades urbanas y rurales.

Los eclesiásticos, en cambio, en general fueron reticentes a delegar poder, y si aceptaban la comuna no dejaban de intervenir nombrando y controlando a los oficiales. Sobre las razones de esta actitud, el autor tiene en cuenta una serie de elementos que difieren de las explicaciones convencionales. Considera, por ejemplo, la forma de gestión de la reserva, basada en la capacidad de exigir prestaciones según requerimientos productivos cambiantes; puesto que los fueros burgueses limitaban la arbitrariedad señorial, la oposición a la comuna estaría en parte ligada a la composición de la renta. Una concepción doméstica y patrimonialista explicaría la tendencia a intervenir sobre el burgo y a recurrir a criados y allegados antes que a sectores ajenos a la casa señorial; otro factor es la extensión del dominio, que de ser controlable en términos prácticos, como en el caso de Sahagún, permite prescindir de personal político extraño al núcleo eclesiástico local. El vínculo de explotación supone un distanciamiento, que en los eclesiásticos está dado por la sacralización, por lo que el alejamiento físico no se presenta como un requisito relevante. La negativa eclesiástica a ceder autoridad se explica también por la ideología de la Reforma Gregoriana, que llamaba al clero a subordinar a los laicos, y de manera central, por el imperativo de controlar de cerca la conducta de los pobladores y detectar cualquier 
indicio de desviación, y en especial, herejías, un objetivo que requiere agentes formados y una vigilancia minuciosa que no puede ser ocasional; estos elementos determinan la importancia de la actuación de cuadros de la Iglesia en el terreno y del control de los dispositivos del gobierno urbano.

Para concluir con el análisis de los aspectos estructurales el autor considera las raíces del antisemitismo, dado que en las revueltas comunales hubo ataques a judíos. Siguiendo a Abraham Léon (y a Marx) plantea que la oposición al judío se relaciona con su especialización comercial, siempre resistida donde predomina la lógica de consumo; la exclusión social de un pueblo comerciante sería una expresión del lugar intersticial del capital mercantil en sociedades en las que no se ha desarrollado el capital productivo y la ganancia sólo proviene de la diferencia de precios, que no deja de percibirse como fraude a compradores y vendedores. La especialización económica de un gupo social con pautas culturales propias hace de los judíos un pueblo clase. Este pueblo clase no es ajeno al dinamismo de los demás pueblos del periodo, que se agregan a clanes vencedores o admiten a los vencidos en su seno, adoptando o transmitiendo el núcleo de una tradición (uno de cuyos componentes es el mito fundacional). La adhesión de otros grupos a la tradición de los judíos explica su multiplicación, que es entonces expansión del judaísmo y no de los judíos, lo que armoniza con el aporte de disciplinas que refutaron la continuidad biológica. El desarrollo de una clase de comerciantes cristianos conlleva el desplazamiento de comerciantes judíos de los circuitos del intercambio (lo cual se constata desde el siglo XI); este desplazamiento, además de presentarse como conflicto religioso, conduce a una reconversión hacia el préstamo y el arrendamiento de rentas, lo que profundiza la reprobación social hacia todo el grupo, percibido ahora como responsable del empobrecimiento o la pérdida de la tenencia por deudas. La prédica estigmatizadora de la Iglesia (sobre lo cual el autor volverá más tarde) contribuye a deteriorar la imagen del judío, quien a diferencia del prestamista de la aldea no tiene inserción en la comunidad, y a diferencia del prestamista aristocrático no tiene una fuente de legitimación ni el imperativo de resguardar la base agraria del que paga renta. El autor considera que en la animosidad hacia el judío, identificado con el usurero, se expresa la tensión entre el lucro y la lógica de consumo.

La tercera parte del libro es el estudio de las luchas. El autor analiza la insurrección de Sahagún y la de Santiago de Compostela, y aspectos de los movimientos comunales de Lugo, Cremona, Colonia, Roma, Cambrai, Metz, Beauvais, Laon, Vézelay, Le Mans, Brujas, Gante, Toulouse, Bury St Edmunds, Abingdon y St Albans. No faltan referencias más breves a movimientos análogos en otros lugares y tiempos y atras luchas, como la de los ciompi o la de 1381. Nos toca transitar un segmento muy arduo, el de los acontecimientos, que resulta inviable referir. Este tramo del análisis de las luchas tiene como sujeto a "los burgueses": el relato se concentra en la elite del burgo, sector que impulsa las revueltas y con el cual dialoga el poder.

Veamos los aspectos más salientes del movimiento de Sahagún, teniendo en cuenta que el caso no proporciona un modelo, ya que en otros lugares las revueltas tuvieron otro curso, otro detonante, etc. (dejo al lector la tarea de incursionar en estos otros casos). El segmento insurreccional de la lucha del siglo XII se inscribe en el conflicto entre el poder laico y eclesiástico propio de los tiempos de la Reforma Gregoriana y en la rivalidad entre la reina Urraca y Alfonso de Aragón, circunstancia que no puede esgrimirse como causa porque las protestas comienzan antes (con la oposición al horno señorial) y continúan después, pero que es parte central del escenario porque las altas esferas dirimen sus conflictos a través del movimiento comunal, y porque los burgueses buscan alianzas en estos niveles para conseguir sus objetivos. Urraca tiene el apoyo del monasterio, y Alfonso, el de los burgueses, quienes aprovechan el enfrentamiento de los dominantes para obtener un espacio institucional. El arribo de las fuerzas del rey de Aragón en Sahagún precipita los sucesos, que incluyen la redacción de un fuero por parte de los burgueses y la pretensión de que se lo reconozca. El movimiento combina huelga de renta (el censo del horno), estallidos de violencia, ataques a propiedades del monasterio, negociaciones, pequeños motines, treguas, resistencia larvada, avances y retrocesos. En su transcurso los burgueses se comportan como feudales: hacen y deshacen alianzas, devastan campos para desabastecer al enemigo, toman tierras, tratan como feudo a la ciudad y no olvidan que la subordinación implica derechos; la posición del burgués en este marco se compara de hecho con las capacidades y límites 
del que es señor y vasallo de otro. El autor destaca aspectos de la subjetividad de los burgueses, como el afán de tratar con personas de jerarquía, y cualidades políticas como la plasticidad ante circunstancias cambiantes o la evaluación meditada de las acciones a seguir, lo que no implica un plan trazado sino la capacidad de adaptación al balance de fuerzas y a las oportunidades que ofrece cualquier signo de inestabilidad o debilidad ocasional del poder.

El objetivo de los burgueses es asentar su dominación mediante el control del gobierno urbano, a la manera de los señoríos colectivos de la Extremadura; no se oponen al régimen señorial sino al señorío eclesiástico, que les niega el manejo del municipio, y por eso la subordinación a otra fracción de la clase dominante no se presenta como problema si se traduce en prerrogativas. En palabras del autor "admitieron ser vasallos con ascenso social", estrategia que no debe despreciarse, dado que para conseguir ese ascenso debieron luchar, y en el transcurso de la lucha se consolidaron como factor político a tener en cuenta por la clase de poder, aun cuando el concejo que lograron haya sido disuelto. Este objetivo incumplido es la causa de renovadas protestas en los siglos XIII y XIV, focalizadas en la cuestión del nombramiento de oficiales, facultad que el abad se empeña en retener. Estas protestas, en cuyo desarrollo se replica la dinámica de idas y venidas a las cumbres de la política, involucran acciones mucho más radicalizadas, como la organización de una suerte de huelga general para desabastecer al monasterio, y tienen lugar en un contexto modificado por el proceso de centralización, que hace de la monarquía un actor dispuesto en otros términos a favorecer la reproducción del patriciado. La negativa sistemática del abad a delegar poder y la disposición también sistemática de los burgueses a luchar por conseguir esa delegación de poder explican el carácter prolongado del enfrentamiento, en cuyo transcurso el objetivo de autonomía municipal por momentos se desliza hacia la oposición al sistema. El hecho demuestra el potencial de las luchas del XII, que pueden dar lugar a movimientos más radicales (el ejemplo más claro aquí es el de Bury St Edmunds). En este sentido, el autor se opone a la dicotomía entre combates institucionales y combates que afectan los cimientos del modo de producción, dado que el devenir de la praxis social puede llevar a objetivos impensados; así como la lucha por el horno doméstico llevó a la lucha por el concejo, ésta puede llevar a la lucha contra el señorío. Por otro lado, el subalterno que acumula en el marco del sistema feudal pretenderá una posición acorde a ese enriquecimiento, el cual también puede dictarle metas que conducen a confrontar con el señor de manera más radical.

La inestabilidad de los dominantes es uno de los elementos que subyace a las revueltas urbanas y a otras luchas en las que los rebeldes avanzaron ante situaciones de vacío de poder, para lo cual se propone el concepto de crisis de dominación feudal (acotado a la superestructura, a diferencia del de crisis orgánica). En el terreno de Gramsci, el autor considera la categoría de consenso, cuya universalidad es obra de los historiadores, ya que no habría sido pensada para sociedades precapitalistas; la disociación legal de las clases niega la igualdad formal sobre la que opera la noción de consenso, contraria, por otro lado, a la descalificación sistemática del subalterno que caracteriza al discurso feudal. Pero la irrupción del patriciado como articulador social entre señores y campesinos introduce nuevas formas de comportamiento político entre los dominantes, como el de tratar con un colectivo o el de hacer abstracción de la inferioridad estamental de este colectivo. De la necesidad de consensuar con estos sectores surgen formas más sofisticadas de actuación, que recogen la experiencia de las luchas y ponen en práctica alguna forma de sistematización, del tipo de la que fue materia de la obra de Maquiavelo.

El resultado más trascendente de la lucha comunal, según concluye Astarita, es la conformación del patriciado como estamento entrenado en la política, entrenamiento que no tuvieron los burgueses que consiguieron autonomía municipal por delegación pacífica del señor, sin formarse en el conflicto ni en el juego de alianzas de los poderosos. Las hermandades y otras formas de asociación que practicaron los burgueses anticipan organismos de la sociedad civil, como el partido político; los vínculos que establecieron con otros movimientos y con otros poderes aportaron a la conciencia del alcance de los intereses y del impacto de las acciones; gobernar una comuna requirió personal que prefigura a la burocracia; haber logrado ese gobierno consolidó la noción de que un objetivo se puede realizar. La lucha por la organización del concejo, en suma, y la 
memoria social de esa lucha, constituyen pilares de la conciencia de clase de la futura burguesía, y contribuyen a sentar las bases de una clase política y de otras instancias del Estado moderno, como las organizaciones de la sociedad civil o la mediación parlamentaria, cuyo principio básico está presente en la eventual incorporación de representantes de la comuna en instancias consultivas. Estos efectos del movimiento comunal sólo pueden apreciarse desde la posteridad -y cabe agregar, desde el interés del historiador en el problema-.

El patriciado naciente acaba enquistándose en el gobierno urbano (que favorece el desarrollo de su actividad ganadera), lo que dará lugar a luchas antipatricias motorizadas por otros plebeyos enriquecidos que aspiran a participar del poder. Este sería el caso, por ejemplo, de los sectores pecheros que cuestionan a la oligarquía urbana en concejos castellanos bajomedievales (el autor cita el memorial de agravios de Ciudad Rodrigo), lo cual difiere del enfoque que considera este tipo de conflicto en términos de idearios contrapuestos.

El patriciado no estuvo solo en las revueltas comunales, y aquí es necesario distinguir entre el sector enriquecido del artesanado y el conjunto formado por artesanos pobres, marginales, mancebos y aprendices cuya presencia se confirma en la mayoría de los movimientos y en las referencias a una turba exaltada, a sectores "viles", etc. Estos sectores tuvieron comportamientos diferenciados (y de hecho el capítulo que trata el tema se denomina "Combates específicos", lo que sugiere su segregación respecto al núcleo que impulsa las revueltas). Entre los artesanos pobres, por ejemplo, tiene prioridad la apropiación de recursos privatizados por el señor, y a diferencia de la elite del burgo, que también se apoderó de tierras, los artesanos modestos habrían considerado la posibilidad de socializar los bienes. El autor destaca la diferencia entre el ideal del campesino medio de generalización de la propiedad individual y las metas de asalariados y sectores más pobres y más radicalizados que no descartaban compartir lo apropiado. La ética de la distribución también aparece en diferentes clases de bandidos, una tipología social que se analiza en base a ejemplos puntuales de diferentes movimientos, lugares y tiempos, personajes de la literatura y figuras legendarias como Robin Hood. El comportamiento fluctuante de estos sectores que alternan el vagabundeo y la delincuencia se explica por la inestabilidad estructural y la dificultad para la integración del que vive en los márgenes del sistema, lo que no impide que hayan tenido organización, división del trabajo, colaboradores, protección cuando eran perseguidos y simpatías entre los subalternos cuando redistribuían el producto del robo o daban muerte a una figura impopular. Más numeroso es el sector de mancebos, jóvenes turbulentos sin objetivos definidos cuyos actos expresan "un impreciso desafío contra el autoritarismo del señor".

El recurso a la violencia (incendios, saqueos, asesinatos) es una herramienta de los sectores populares, cuya fortaleza está en el número. La movilización de una masa dispuesta a la violencia decide en muchos casos el curso de los acontecimientos, lo que hace de la multitud un factor político no desdeñable para el patriciado, aunque queda por descifrar el nexo entre la elite y sus seguidores, que se resolvería en el campo de la psicología social. El autor explica la eficacia del recurso a la violencia por el efecto que produce en el adversario señorial, que pasa de la descalificación del subalterno a la conciencia del peligro y del miedo al terror, que lleva a la huída o a la decisión de dar batalla, y que favorece la cohesión de la clase dominante. Plantea que el acto de infundir terror en los poderosos, que es el arma de la multitud, invierte los términos de la relación social, fundada en la coacción, y explica el terror blanco que sobreviene a diversas agitaciones. Este tipo de acciones descubren una racionalidad potencialmente disruptiva: el ataque a edificios y bienes de prestigio (que no es caótico sino articulado) es un ataque a dispositivos no económicos de dominación señorial, y aunque los insurgentes no descifraran este sentido, la destrucción de símbolos del poder desmitificaba y construía "un lenguaje de clase estamental" que no dejaba de resultar liberador.

El autor se detiene en la escena de la crónica compostelana que describe el momento en que la reina es apedreada y arrastrada en el barro con su vestimenta hecha jirones. En este "ritual de degradación" se expresa la misma inversión de jerarquías que en el carnaval que describió Bajtin. Despojar al oponente de los elementos que evidencian su lugar en la sociedad es una forma de negación del orden social, negación que en sociedades precapitalistas, en las que la relación social no se presenta como relación entre objetos, 
se manifesta en el rechazo al privilegio visible de la persona. El autor compara estas formas de lucha con las del proletariado moderno, que además de tener una dirección definida no atentan contra individuos sino contra el interés del capitalista. La algarabía que suscita la reina humillada se inscribe en la estética popular, asociada al sarcasmo, la ironía o el humor; estos ingredientes, que se registran en episodios puntuales de las revueltas, también se dan cita en prácticas como beber y comer desaforadamente, prácticas que los cronistas y algún historiador consideraron irracionales, y que aquí se entienden en términos de "reparación fisiológica" e "infracción simbólica".

Otro componente de la radicalidad de las masas es su noción particular de la justicia, que niega al acusado el derecho a defenderse; esto se atestigua en la práctica del juicio popular y en otras iniciativas destinadas a suprimir a quien ha sido tildado como enemigo. Aquí interviene otro elemento prepolítico: la búsqueda de aceptación de las decisiones por unanimidad, alcanzada mediante amenazas, recompensas o la obligación de jurar fidelidad, y también producto del estado de ánimo de las masas y de la imposibilidad de sustraerse de las decisiones colectivas. Dada la forma en que se lograba la unidad tendríamos en el movimiento insurreccional una sumatoria de voluntades o conciencias críticas singulares antes que unidad de clase.

En cuanto a las metas y los mecanismos por los que se generaba un movimiento masivo, se consideran desde móviles o detonantes circunstanciales (una afrenta, un abuso, una disputa en el mercado) hasta la adhesión consciente a algún tipo de ideal; el autor destaca el carácter premoderno de este tipo de movilización, que sólo es una totalidad desde la percepción distorsionada del señor, y el perfil "casi revolucionario" de estas formas de lucha, que impugnan el orden social sin construir una alternativa superadora.

El carácter masivo de la insurgencia se relaciona también con la difusión de noticias (asociada a la movilidad de los dependientes), la divulgación de contenidos disruptivos en canciones y poemas, y el papel de agitadores surgidos de los oficios, cuya presencia se registra en diversos movimientos. Volvemos aquí a la centralidad de las cualidades del oficio artesanal y del ámbito de trabajo del artesano, que favorecen su politización. Tanto en Sahagún como en otros movimientos se observa el protagonismo de zapateros, que Hobsbawm consideró entre los elementos más radicalizados del artesanado; el autor analiza el vínculo entre trabajo manual y práctica intelectual: a diferencia del místico, que intenta acceder a la esencia de Dios desde la fe y el sometimiento a una idea, el artesano intenta acceder a la esencia del objeto mediante el conocimiento profundo de todo lo que encierra el procedimiento para crearlo, conocimento que construye gradualmente desde la práctica manual y la reflexión. El hecho de figurarse antes el objeto que va a fabricar favorece asimismo la posibilidad de elaborar conceptos. El interés por parte del artesano en dominar el oficio está asociado al reconocimiento social de su actividad, que alimenta ya no la autoestima sino la "jactancia egocéntrica", para el autor una actitud positiva que tal vez se ponía en juego también cuando el artesano hablaba en una asamblea. La creatividad y la manera de procesar la información que implica el trabajo del artesano favorecen el desarrollo de una conciencia crítica intelectual y el despliegue de atributos asociados como la oratoria, ligada también a la necesidad de argumentar, lo cual explica la proliferación de dirigentes y agitadores. Influye también el desarrollo de las escuelas urbanas, a las que pudieron concurrir sectores burgueses. Se destaca la influencia del movimiento comunal sobre el pensamiento filosófico, al que impuso una agenda renovada de problemáticas, como la necesidad de teorizar sobre la práctica política y de revisar toda doctrina fundada en la armonía y el orden natural de las cosas.

La última parte del libro se centra en la cuestión religiosa. El anticlericalismo, "tal vez la única ideología de los rebeldes", debe situarse en el contexto de la Reforma Gregoriana, que profundizó la fractura entre laicos y eclesiásticos y generó, como efecto no deseado, movimientos de oposición a los clérigos que contrariaban sus principios y, desde allí, a la estructura eclasiástica en general. El autor pone de relieve la diferencia estamental entre los dominantes, diferencia que a veces se diluye en la prioridad analítica de la clase, y que implica mecanismos específicos de reproducción y distinciones en el estilo de vida, en la subjetividad y en el tipo de vínculo con la dimensión religiosa, que en el aristócrata laico es más bien de tipo práctico y no lo configura como señor. La lucha comunal es inseparable del conflicto derivado de la pretensión de dominio 
pontificio y su no aceptación por parte de poderes laicos, que además de intervenir en el enfrentamiento entre burgueses y eclesiásticos proporcionan a los primeros argumentos contra los prelados que les niegan autonomía organizativa.

El clima cuestionador de la Reforma Gregoriana, el conflicto que suscita entre estamentos de la clase dominante y la posición del sacerdote en el sistema de clases (que lo distingue del hechicero primitivo) son algunas de las condiciones del anticlericalismo. Este fenómeno tuvo amplias manifestaciones en los movimientos comunales, aunque en el caso de Sahagún y Santiago de Compostela los rebeldes no fueron declarados herejes. El autor aporta entonces precisiones sobre la noción de herejía, que no debe limitarse a la definición doctrinal de obstinación en el error; la identificación del dogma con el juicio del papa confluye con lo que ocurre en la práctica: el rótulo de hereje se asocia centralmente al desconocimiento de la jerarquía o de la autoridad. Aquí se discute el enfoque de Robert Ian Moore, centrado en la necesidad de la Iglesia de crear un enemigo, con el argumento de que esta visión minimiza la importancia del comportamiento realmente herético que pudieron tener los acusados de herejía y otros disidentes no alcanzados por la decisión eclesiástica de reprimir. Este sería el caso de los movimientos anticlericales de Sahagún y Santiago de Compostela, que el autor considera en sintonía con las herejías europeas del momento aunque no hayan sido calificados como tales. Rechaza también la noción que atribuye a la herejía un contenido revolucionario, en vista de la adhesión de sectores aristocráticos, aunque la disidencia puede transformarse en lucha contra el sistema. Debido a que algún autor lo postuló, Astarita se ve en la necesidad de aclarar que la herejía no es irreligiosidad.

En la revuelta de Sahagún y en otros movimientos comunales los rebeldes profanaron objetos sagrados, atacaron iglesias y lugares de culto y persiguieron a sacerdotes, lo que se vincula a los contenidos y prácticas de las herejías del periodo. El autor dimensiona el sentido de estas acciones, que expresan la magnitud de la ruptura que implica el movimiento insurreccional, ya que tienen como escenario un lugar de devoción y atentan contra la separación entre laicos y eclesiásticos y entre el sacerdote y la plebe. En la formulación del autor, estos desarrollos expresan "una dialéctica de sacralización oficial y desacralización contestataria”.

La condición más importante del anticlericalismo es el proceso de interiorización religiosa que experimentan los sectores urbanos, ya que esta forma de espiritualidad requiere poco del intermediario, lo que degrada la figura del sacerdote. A diferencia del sectario, que elige romper con su vida anterior, abandona sus bienes y sufre una verdadera conversión, el artesano se comunica con el dios preexistente que ha interiorizado sin modificar su rutina ni sus preocupaciones materiales. (Cabe recordar que en la primera parte del libro el autor discute que el misticismo explique la nueva religiosidad.) La fuente principal de la interiorización de Dios es el distanciamiento respecto al dominio de la naturaleza. El hecho de que esta ruptura en la práctica sea parcial, ya que el artesano conserva una base agraria, no cambia la esencia de las cosas, puesto que es el trabajo en el taller el que hace posible la nueva forma de acercamiento a Dios, que ya no es naturaleza divinizada como en la creencia del labrador. Este contenido de la devoción campesina al pequeño dios local, que no deja de ser el dios vengativo del Antiguo Testamento, implica un proceso abstractivo, porque el santo al que el labrador otorga ofrendas personifica las fuerzas de la naturaleza que no puede dominar. El alejamiento del imperio de estas fuerzas, que se produce en el siglo XI con el desarrollo de los oficios, favorece la evolución hacia una religiosidad interior que supone una divinidad más humanizada y más acorde con una actividad que ya no depende del clima o de circunstancias fortuitas. Esta transformación (que conviene a la esencia del cristianismo) debe entenderse desde el concepto marxista de alienación religiosa (el hombre se subordina a su propia creación, en este caso Dios, que se le presenta como un poder independiente, y enajena en esta creación su propia esencia). La interiorización de Dios es entonces humanización y deshumanización: el servilismo hacia Dios convive con las potencialidades que conlleva su presencia en la persona, que estimula la posibilibidad de que esa persona se forme sus propias ideas acerca de la religión y que prescinda de la mediación del sacerdote. Si bien con esta forma de religiosidad no desaparece el temor a Dios, este temor ahora se asocia a la incertidumbre frente a una totalidad social, y aquí el autor considera la explicación 
freudiana de por qué el hombre se refugia en la religión, sustituyendo el desamparo infantil por el desamparo que produce el alejamiento de la naturaleza.

Con referencias a la filosofía especulativa, Astarita desarrolla las derivaciones del carácter contradictorio de la interiorización religiosa, que opone inferiorización del individuo (dada por la enajenación) y potencialidad liberadora (dada por el rasgo humanista). Esta potencialidad está contenida en las nuevas prácticas que trae consigo la convivencia cotidiana con Dios, como la introspección, que desplaza a la penitencia, y tiene como premisa las cualidades del trabajo artesano, y en especial, su carácter teleológico, es decir, el hecho de ser pensamiento objetivado y no vaga intención. El autor contrasta el trabajo concreto del campesino, subsumido en la acción de la naturaleza y percibido como acto penitencial, y el del artesano, liberado de fuerzas imprevisibles y reconocido como cualidad humana. El desarrollo de los oficios expresa así una dimensión de un problema central en el pensamiento de Marx, el de la separación entre el sujeto y las condiciones objetivas del trabajo, que en la forma de emancipación de la naturaleza que aquí consideramos habilita un lugar a una idea relativamente autónoma de Dios. La disidencia religiosa, por lo tanto, será el problema que enfrentará la Iglesia a partir del siglo XI, a diferencia del periodo previo en el que debía lidiar con la religiosidad pagana del labrador que intentaba conjurar las fuerzas de la naturaleza. La escisión entre sujeto y objeto que operan los oficios se traduce en conciencia de la capacidad creadora por parte del artesano, y por ende autoconciencia, que implica conciencia de la realidad objetiva como producto del trabajo y del productor como ser social, premisa de la ética del ser para otro.

Podría decirse entonces que las cualidades de la actividad laboral del artesano, en un contexto en el que no se ha desarrollado la alienación en el producto del trabajo, favorecen que el sujeto acabe alienado respecto a otra creación suya, Dios, y que a su vez reconozca, en contradicción con este posicionamiento servil, su esencia humana y su potencial transformador (en los límites de la sociedad precapitalista), a lo cual también contribuyen las características de su religiosidad, que se corresponden con las características de su trabajo. Agregaría, respecto al contraste entre el trabajo del campesino y el del artesano, que aquí sí estaríamos ante tipologías o lineamientos generales antes que frente a productores reales.

A diferencia del proceso productivo de las ciudades pañeras, con mayor desarrollo del fraccionamiento de tareas, en Sahagún el artesano produce íntegramente el objeto, por lo que el autor entiende que cabe atribuirle plenamente los rasgos mencionados.

Las revueltas comunales tuvieron el apoyo de minorías religiosas como la de los mozárabes emigrados al área de Sahagún. Este sector debió resistir la persecución de los agentes del papado, lo cual se encuadra en el proyecto imperialista de disciplinamiento de iglesias particulares con pretensiones de autonomía. La defensa tenaz del rito practicado por los mozárabes indicaría que éstos contaban con la adhesión de sectores populares, y que en la resistencia se ponía en juego algo más, para el autor una concepción del vínculo del creyente con el sacerdote fundada en la cercanía social. La adhesión se explica en términos de etnoformación (la elite mozárabe aglutinaba a sectores amplios menos comprometidos a los que daba una identidad). Para analizar las características del grupo Astarita se remonta a su conformación en el estado islámico de alAndalus; considera aquí la noción de afinidades electivas de Weber, ya que preservarse como cristianos habría sido una opción calculada para convivir con los árabes manteniéndose al margen de sus organizaciones clánicas, que por otro lado contradecían el modelo de familia impulsado por la Iglesia en el periodo. En la elección religiosa influyen otros factores, como la tolerancia del Islam hacia las religiones del libro -que sería no sólo doctrinal sino también práctica, dado que los conquistadores requerían de aliados nativos para gobernar-, y la necesidad de darse una identidad definida entre el conjunto de funcionarios intermedios, cuya fragilidad y sujeción al poder central, propia de los estados tributarios, contrasta con el desarrollo autónomo de los gobernantes en el feudalismo. Esta debilidad, asociada al modo de producción, explicaría la emigración. Una vez en tierra cristiana, los mozárabes sufrieron primero la persecución de la Iglesia, que los concebía en términos de alteridad moderada, y luego la pérdida de identidad, que habría sido el costo de integrarse plenamente a la clase dominante. 
La oposición de clérigos a la intervención papal sobre la costumbre de sus iglesias se verifica en muchos lugares, al igual que la conexión entre este tipo de conflicto y los movimientos comunales, en ocasiones apoyados o incluso iniciados por clérigos que no aceptaban las imposiciones provenientes de Roma, y que a medida que se comprometían con el movimiento comunal profundizaban su actitud disidente.

El vínculo entre disidencia religiosa y movimiento comunal se pone de manifiesto también en el caso de los cátaros. El autor destaca la fase inquisitorial de la represión, que establece la prohibición de asociaciones juradas, lo que revela el interés en combatir las comunas y no solo la herejía, de lo cual hay evidencia en otros puntos del sur de Francia más allá del epicentro del conflicto. El apoyo de los burgueses al catarismo se explicaría por la austeridad que predicaban y ponían en práctica los jefes espirituales, que armoniza con la idea de una religión que no suponga gastos excesivos. El patriciado acaba alineándose con la ortodoxia e integrándose al Estado, lo que demuestra que la conciliación fue otra de las herramientas del papado para conseguir la adecuación a sus lineamientos.

Seguidamente el autor vuelve a la cuestión del antisemitismo, desarrollando esta vez los contenidos de la elaboración doctrinal y de diversas formas de propaganda que dan consistencia ideológica a la animosidad preexistente, relacionada con la actuación del judío como prestamista. La noción de pueblo deicida, derivada de la idea de transmisión del pecado a los descendientes, se reafirma en el periodo de las revueltas con agregados sobre la intención de ejecutar a Jesús. Sindicado como el pueblo que ejecutó a Dios, el pueblo judío deviene portador de un estatuto inmodificable e independiente de la voluntad de las personas. La atribución de rasgos físicos con los que se quiere expresar la transferencia al cuerpo del estigma del alma contribuye a configurar la noción del judío como raza, que sustenta la tradición antisemita. El autor repasa la serie de caracteres temerarios que la Iglesia atribuye al judío y los mecanismos por los que va logrando que la imagen que construye se asimile a nivel subconsciente. Para explicar los pogromos que se registran en el periodo considera también la prédica que acompañaba la salida a una cruzada o las peregrinaciones, orientada a exacerbar los ánimos e inducir sentimientos extremos; el hecho de que Sahagún se encuentre en una ruta de peregrinación contribuye entonces a explicar el ataque a judíos durante la revuelta. El autor enfatiza la importancia de las nociones que inculca la Iglesia en discursos y otros dispositivos, que se combinan con normativas que aun cuando apunten a la tolerancia consolidan la idea de discriminación. Pero la cuestión central son las condiciones que hicieron a las masas receptivas a la propaganda eclesiástica contra el judío, condiciones que como se anticipó estuvieron dadas por el desplazamiento de los judíos del comercio en el siglo XI y su reconversión hacia el préstamo, que genera situaciones ruinosas a los deudores. El hecho de que la prédica de la Iglesia, que no comienza en la Edad Media, haya devenido en antisemitismo popular cuando se opera este cambio confirma la primacía del factor económico en la explicación. La comparación con episodios de homofobia en las germanías de Valencia descubre un esquema: el discurso intolerante de la Iglesia opera sobre poblaciones fragilizadas (por la usura, por una catástrofe natural) y en el fragor se impone la noción de separar al otro. El autor reflexiona acerca de cómo se construye esta condición, que puede ser relativa, como en el caso de los mozárabes, a los que la Iglesia quiere asimilar, o absoluta, como en el caso de los judíos, a quienes quiere segregar; ambos grupos elaboran una tradición sobre la noción de pertenencia a un linaje, que en el caso de los judíos resulta incompatible con el mundo de los católicos, dado el estatuto de pueblo enemigo que les otorga la Iglesia; la segregación se profundiza cuando a este rótulo oponen el de pueblo elegido. La debilidad de la instalación y la tendencia a la endogamia producto de una existencia instersticial en un medio hostil (que a su vez refuerza el refugio en una tradición) son otros de los factores que considera el autor, que también repasa testimonios modernos de antisemitismo provenientes de diversos frentes.

En las revueltas comunales hubo agitadores surgidos del ámbito eclesiástico, lo cual se explica, en parte, por la ampliación de la base de reclutamiento del clero, constituido por un núcleo duro comprometido y un extenso conjunto de tonsurados cuyo nivel de adhesión no era tan firme. El aspecto del fenómeno que aquí se trata es el perfil de los agitadores y el tipo de vínculo con las masas. Accedemos a ejemplos concretos, como el discurso de un agitador de Santiago de Compostela que desde la crítica moralista redirige a la audiencia 
contra el señor, o los caracteres que los cronistas atribuyen a Arnaldo de Brescia, que dejan ver la eficacia para convencer y la profundidad del mensaje. El autor se detiene en la figura de este agitador de la causa comunal, de quien ofrece una biografía y de quien destaca la capacidad para expresar exitosamente el inconformismo de las masas.

La oratoria es una cualidad de los agitadores vinculada al tipo de entrenamiento que daba el método de estudio en las escuelas urbanas, fundado en la polémica y en la defensa oral de la argumentación; otro rasgo es el estilo de vida itinerante, propio de predicadores e intelectuales, que no dejaba de resultar perturbador en una sociedad en la que la movilidad se concebía como privilegio. Con este tipo de intelectual surge una nueva forma de existencia, la de la persona que se realiza en su actividad. Esta supone, al igual que para el monje, un alejamiento del mundo, o de las preocupaciones mundanas, como lo señaló Eloísa, aunque a diferencia del monje el agitador vuelve al mundo para enfrentarlo.

Astarita desarrolla el contraste entre el intelectual que acompaña las luchas con la actitud de subordinación a las decisiones de la masa, y el que se disocia de la masa tomando su lugar y anulando su protagonismo, contraste que resume como el pasaje "del foco luminoso al foquismo", y en términos de teoría política, "del intelectual orgánico de la clase al inorgánico hombre sin clase que inhibe la lucha de clases". También aquí hay un paralelo entre la ruptura del sectario y la del monje, para quien "el nuevo mundo empieza con su mundillo". Esta evolución del movimiento social a la secta es la que distingue a Arnaldo de Brescia de los posteriores arnaldistas, y tiene un ejemplo en los apostólicos de fray Dulcino, relacionados con el movimiento comunal de la Baja Valsesia, en Lombardía. La derrota de esta secta se explica por el aislamiento de la base social, la diferencia entre la simpatía que podían despertar y el compromiso real (diferencia que no escapa a las fuerzas represivas de todos los tiempos), el desgaste que producen las profecías incumplidas y el carácter parcial de la aceptación del mensaje entre sectores urbanos, cuya adhesión tiene un límite en la defensa de la propiedad. El carácter selectivo de la recepción del discurso se puede adivinar en el caso de John Ball y su noción de comunismo primitivo, que no podía atraer a todos pero sí a los carenciados de propiedad. Ball, por otro lado, ejemplifica al dirigente que sabe conducir a la multitud y "hacer ver a todos lo que ya saben".

La lengua no sería un problema para el orador que se desplaza, dado el carácter trasnacional de una audiencia acostumbrada a la diversidad, la práctica de la traducción y el formato bien estructurado del discurso, que facilitaría su comprensión. Contribuyen a la difusión de ideas los lugares de sociabilidad (la taberna, el cementerio), los caminos de peregrinación y los desplazamientos de comerciantes. La variada localización de la cultura, como lo demuestran los intelectuales que llegaban a París ya formados, expresa una trama de circulación de ideas. En cuanto a su recepción por las masas, el autor tiene en cuenta factores anímicos como el efecto movilizador que podía tener la actuación de un juglar en una plaza acompañando con gestos y artilugios visuales la crítica al sacerdote. Contrasta esta búsqueda de empatía con el público con la segregación que propone el ritual incomprensible de la misa.

Entre los rasgos del intelectual Astarita se refiere a la soberbia, un vocablo que aparece en las crónicas para denostar la altanería de un artesano o de un agitador. El combate de la Iglesia a este posicionamiento, tipificado como pecado, no se explica solamente porque contradice la humildad que se pregona para el cristiano sino por la amenaza que representa para el orden social la actitud del que se guía por sus propios criterios y elige qué hacer con su vida. El autor destaca la percepción positiva que tenía de sí mismo un artesano o un filósofo y su potencial, si la autovaloración se proyectara a nivel colectivo (lo cual habría sido entrevisto por Hobbes, cuyo Leviathan se orientaría a prevenir este escenario antes que a reprimir la libido individual de dominación). Centrado en la idea de magnanimidad, Astarita vincula la actitud jactanciosa del tipo social urbano con las revueltas comunales, ya que la conciencia de las potencialidades humanas conduce a la rebelión.

El sentimiento de superioridad como novedad del periodo puede verse en la autobiografía de Abelardo, cuya vocación manifiesta de destruir al oponente armoniza con el espíritu de la lucha comunal. Ésta también se vio favorecida por los hábitos escolásticos: el método dialéctico implica el planteo de interrogantes y 
un recorrido de razonamientos críticos para llegar a la verdad, recorrido que incluye la negación, al menos temporaria, de afirmaciones del dogma, lo cual no deja de ser un cuestionamiento a la autoridad. En este contexto destaca la contribución de Abelardo: la solución conceptualista al problema de los universales implica la posibilidad de reflexionar desde la prioridad analítica de la realidad objetiva, lo que anticipa un enfoque materialista; la ética de la intención armoniza con el comportamiento del agitador (o del artesano) que se guía por sus convicciones y toma decisiones en los límites de lo posible o lo aceptable. Esta forma de actuar tendría una expresión en la práctica política urbana, que se despliega según las circunstancias contemplando estrategias convenientes al objetivo, no siempre en línea con principios morales aunque dictadas por éstos en última instancia, al menos en el caso de figuras como Arnaldo de Brescia. Aquí se trata la moral del agitador del movimiento comunal, asociada a una vertiente de la ética del cristianismo, la dedicación al prójimo (coexistente con el principio de salvación individual), que conduce al sacrificio por el otro, una conducta que anticipa la inmolación del militante revolucionario, o de alguno de sus exponentes. Al respecto, Astarita adjudica a la formación cristiana la predisposición al martirio de líderes de Montoneros o del ERP provenientes de la clase alta, lo que señala cierta conexión entre estos líderes y los agitadores de las revueltas del XII.

Cuando el intelectual combina la teoría y la acción, o cuando el habitante del burgo pasa del reproductivismo cotidiano a la modificación de las condiciones dadas, se abre la posibilidad de sistematizar los distintos aspectos de esa experiencia, y con ello la posibilidad de plantearse un proyecto político, con lo cual la transformación social ya no queda librada al devenir de los acontecimientos. En relación a la perspectiva de elaboración teórica se consideran las condiciones para el desarrollo del racionalismo crítico. Siguiendo a Francis Oakley, Astarita enfatiza la protección que significó para el intelectual la autonomía universitaria, un factor al que propone sumar la fragmentación política y la consiguiente disputa interfeudal, que permitió que la labor intelectual se realice bajo el amparo de uno u otro señor, o que un pensador disidente tenga la protección de un aristócrata laico enfrentado a la Iglesia, posibilidades que no tuvieron los intelectuales de los estados despóticos orientales, subordinados al arbitrio del poder central. Estas condiciones favorecieron la posibilidad de desarrollo de doctrinas que pudieron inspirarse en el movimiento comunal, como las que dieron fundamento filosófico a la separación de la esfera de la religión, o dar sustento teórico al movimiento comunal y a desarrollos posteriores, como en el caso de la crítica de Arnaldo de Brescia a las posesiones de la Iglesia o a la aspiración eclesiástica de gobierno. En este sentido, las revueltas contribuyeron a la formación de la política como teoría y práctica del conflicto y al perfil laico del Estado.

El libro termina con esta reflexión: el hecho de que el sector patricio a la larga haya proporcionado intelectuales orgánicos a la clase dominante para combatir la disidencia no desmerece el valor de las luchas del XII, que "renovaron el feudalismo" y demostraron, al igual que otras luchas, que no es imposible cambiar las condiciones existentes.

\section{ACERCA DE LA FISONOMÍA GENERAL DEL LIBRO}

Lo expuesto hasta aquí puede dar una idea de los contenidos troncales de la obra, que, recordemos, tiene cerca de 1200 páginas, lo que implica que muchos desarrollos analíticos han quedado en el camino. Comparto ahora algunas impresiones y un ejemplo sobre el método.

Muchas de las formulaciones que hemos sintetizado surgen de conexiones que establece el autor entre testimonios de diversas protestas comunales y otras luchas, lo cual imprime al libro una fisonomía particular. Veamos un ejemplo. Se está analizando la destrucción de símbolos de poder por parte de la multitud, un problema impuesto por la crónica que describe el ultraje a la vestimenta de la reina Urraca durante la revuelta: la evidencia empírica ha dictado qué buscar y en qué pensar. El autor piensa en estos bienes como objetos portadores de estructuras y como capital simbólico, lo que le permite dimensionar lo que implica destruirlos, y observa que en Santiago de Compostela los rebeldes robaron prendas de vestir y vasos de oro y plata del palacio 
del obispo, y que los rebeldes ingleses de 1381 quemaron ropa de una residencia aristocrática, lo que revela un mismo propósito de invadir la intimidad señorial; que también saquearon tesoros los de St Edmunds en 1327, quienes además quemaron cartas de privilegio especialmente valiosas para los monjes; que este desprecio a lo que valora el aristócrata lleva a pensar en las acciones del "tercer estado" en el contexto revolucionario, lo que nos conduce a la burguesía; que el contraste entre la percepción burguesa del lujo y la aristocrática está retratada en un diálogo de El Fantasma de Canterville en el que el desprecio burgués a los objetos de prestigio se opone al aprecio no monetario de esos bienes por parte del aristócrata, lo que demuestra la dimensión histórica de esa oposición; que en la protesta de Sahagún y en la de Laon se presenta una variante, el asalto a las provisiones señoriales de comida y su desperdicio; que también atacan la despensa señorial los rebeldes de 1381, quienes aprovechan la ocasión para vender el grano, lo que indica que el sustrato arcaico de estas conductas, que recrean el banquete comunitario, puede tener otros tintes que no anulan el sentido principal; que en la marcha de Kent hacia Londres los rebeldes se desplazaban tranquilamente, lo que confirma que esos ataques a fortalezas señoriales respondían a una planificación; que el elemento de coordinación y el sentido preciso de los actos aparece en el caso de los pobladores de Segovia que en 1520 destruyeron los cántaros en los que se medía el impuesto al vino, en el de los agermanados de Valencia que quemaron escrituras en la plaza, en el de los rebeldes de Vézelay que se reunieron para coordinar acciones, etc. Esta estructura compositiva, en la que un testimonio conduce a otro y en la conexión se descubren significados, se encuentra en muchas de las problemáticas que se tratan en la obra, con variantes en la materia prima con la que trabaja el autor.

El libro es desmesurado. La extensión no está dada por la repetición ni por desarrollos descriptivos de una idea central sino por la incursión constante en situaciones de otros lugares y tiempos, que como vimos responde al método; la extensión obedece también a la reflexión en torno al problema específico que se está tratando, que habilita desarrollos críticos laterales. Por ejemplo: el autor está analizando el origen del artesano, que vincula con el esclavo tempranomedieval, y una parte de la explicación radica en la conducta de los señores que favorecieron la instalación, mientras otros preservaban la forma antigua. Aquí se abre una reflexión, ya que la observación "destruye la tesis sobre la rentabilidad comparativa que se esgrimió para explicar a los servi casati"; seguidamente se exponen una serie de argumentos contra esta tesis, con referencias a la esclavitud en Estados Unidos, en el mundo clásico, etc. Así es como los problemas se multiplican.

El libro tiene registros variados. La exigencia de la argumentación, la forma de sistematizar o el recurso a materiales y elaboraciones que puedan iluminar el problema que se está tratando dan lugar a tonos muy disímiles. El lector transita por distintas claves expositivas: desde el registro puramente teórico hasta el de la historia fáctica y la relación no convencional de acontecimientos (por ejemplo en torno a las revueltas o a las herejías); dentro de la diversidad de registros narrativos debe ponerse de relieve la elaboración literaria en torno a fuentes, como el relato sobre el obispo de Santiago de Compostela que roba reliquias y las traslada exitosamente hasta sus tierras (pp. 171-172), para dar un ejemplo particularmente destacado, ya que la composición en clave literaria es un recurso frecuente en la obra. Por momentos la exposición avanza mediante afirmaciones generales fundadas en bibliografía, lo cual replica el registro de la sociología histórica; en otros casos la reflexión es distendida, como cuando se tratan contenidos de obras literarias y crónicas, por ejemplo los referidos a personas y personajes que cayeron en la marginalidad a partir de una experiencia traumática de maltrato o de rechazo.

Si bien hay segmentos en los que predomina una u otra forma expositiva, en general la elaboración de un problema combina el relato, el análisis conceptual, la reflexión del que piensa en voz alta y la sistematización; así, por ejemplo, en un mismo párrafo una nota de color convive con el lenguaje de la dialéctica: el maltrato a Urraca, cuestionando el orden social sin proponer nada, es un "que se vayan todos" y una "no radicalidad de la negación que se niega como afirmación superadora”.

El libro está fundado en la conexión entre pasado y presente. Esto no es solamente la declaración de un principio teórico sino un ejercicio constante, lo cual coloca también al lector en esta clave. La experiencia de las luchas del siglo XX proporciona elementos para comprender aspectos de las revueltas comunales, así como 
las luchas del siglo XII llaman a reflexionar sobre prácticas políticas actuales. Así el fracaso de una cofradía de herejes que se alejó de las bases anticipa el fracaso del paso a la clandestinidad en la década del setenta, o el de las fuerzas políticas que hoy prescinden de las masas, o estos fracasos ayudan a entender por qué fracasaron los apostólicos, etc.

El fracaso del socialismo real es una de las frustraciones que recorre el libro; se explicita en relación a la necesidad de superar el mecanicismo teórico, que ignora al sujeto, y la confianza en los pueblos, que no evalúa condiciones objetivas, y está presente aquí y allá, en referencias circunstanciales, como la que se hace sobre la preocupación socialista por inculcar una ética proletaria que pierde de vista el fundamento objetivo y subjetivo de las acciones. La temática del libro, centrada en los intentos de un sector de luchadores por crear una forma política viable y acorde a sus intereses, podría vincularse también a una inquietud más general, al igual que el interés por descifrar el plano de la subjetividad de las masas.

Por momentos la reflexión se consagra a cuestiones de actualidad, como en el análisis de la escuela de subalternidad (pp. 137-149), cuyo auge el autor explica por la necesidad del capital de homologar la fuerza de trabajo susceptible de explotación, a lo cual contribuyen las luchas contra la opresión fundada en elementos étnicos, raciales, sectoriales, etc. La actualidad se da cita en clave comparativa, como la referencia al contraste entre las elites plebeyas medievales, reconocidas como tales por la clase dominante, y la tendencia del capital a subsumir a todas las capas de trabajadores, incluidos los que hoy no imaginan que acabarán afiliados a la CGT, según advierte el autor. La referencia a cuestiones actuales aparece también como comentario al paso: por ejemplo, el autor está analizando la toma de tierras por parte de los burgueses durante la revuelta de Sahagún, que afecta posesiones de los labradores, lo que lo lleva a advertir sobre el error populista de creer que los pueblos enfrentan a una elite muy reducida (y aquí uno recuerda la sorpresa que produjo en las últimas elecciones que un proyecto depredador obtenga el $40 \%$ de los votos).

El libro prescinde de ciertas convenciones académicas. Lo ilustra el análisis sobre la miseria de la escuela de los Annales (pp. 39-40), o los comentarios sobre el "ensayismo vaporoso" de Guerreau, "aplaudidos charlatanes como Foucault", cierto "proceder antediluviano", o "un pontífice de la corporación de historiadores" que será tratado de asno por negar lo que dicen las fuentes castellanas sobre la falta de lana (y aquí hay que decir que el libro es divertido). Para el autor analizar por qué en las últimas décadas no se estudiaron las revueltas comunales implica necesariamente exponer a los que aludieron al tema a la ligera, siguieron una moda o no pensaron en lo que afirmaban (por ejemplo, el que postuló que "a veces hubo fricciones" en referencia al asesinato de un señor); de igual manera, Astarita no puede limitarse a explicar por qué es incongruente atribuir al concepto de modo de producción el rango de tipo ideal; necesita añadir que los que realizan esta operación no conocen la filosofía de manual. El manual de filosofía también se recomienda a los que descalifican por teleológico el hecho de abordar un problema en base a los efectos que revela la posteridad, y así podríamos seguir brindando ejemplos del impiadoso trato a los académicos (que por otro lado, alcanza a todos, ya que se condena, por ejemplo, la microhistoria, una noción que puede incluir estudios regionales si el punto de referencia es esta obra). Por fuera también de los parámetros convencionales la presentación de las crónicas y la fundamentación de su verosimilitud aparecen en ocasión de la crítica a los cultores del giro lingüístico. Ya que el autor no sigue las convenciones, tal vez podría haber abandonado también el mandato de citar en el idioma original, que distancia gratuitamente al lector.

El libro es desprejuiciado. Los burgueses del siglo XII se comparan con el primer gobierno de Perón (en la caracterización que hizo Di Tella, que sirve para superar las visiones dicotómicas que sitúan al burgués en el pueblo o en la nobleza); Rambo ilustra los limitados recursos de un agente señorial que se defendió de la multitud con la espada; el héroe de la independencia Martín de Güemes y el anarquista Severino di Giovanni ejemplifican lo que el paso del tiempo puede hacer con un bandido.

Es claro que de aquí en más ningún estudio sobre sectores urbanos medievales podrá eludir esta elaboración. Pero lo que aporta excede los límites de las especialidades. El libro es una fuente de ideas para el historiador de la Edad Media que trabaje uno u otro aspecto de la historia social, y nutrirá también a los 
interesados en la lucha de los subalternos en general, dentro y fuera del ámbito académico; en la reformulación de enfoques, teorías y prácticas políticas se verá la contribución más trascendente de la obra, la cual, al igual que la totalidad que quiere explicar, es devenir, y por lo tanto objeto inacabado, materia de otra cosa. Con este espíritu debemos transitar el libro, y pensar en qué nueva etapa del análisis de las luchas populares nos encontramos ahora.

\section{Notas}

1 ASTARITA, C. (2019). Revolución en el burgo. Movimientos comunales en la Edad Media. España y Europa. Madrid: Akal. 